\title{
Identification of a G2-like porcine rotavirus bearing a novel VP4 type, P[32]
}

\author{
Patrick J. Collins ${ }^{1}$, Vito Martella ${ }^{2}$, Canio Buonavoglia ${ }^{2}$, Helen O’SheA ${ }^{1 *}$ \\ ${ }^{1}$ Department of Biological Sciences, Cork Institute of Technology, Rossa Avenue, Bishopstown, Cork, Ireland \\ ${ }^{2}$ Department of Veterinary Public Health, Faculty of Veterinary Medicine of Bari, S.p. per Casamassima Km 3, \\ 70010 Valenzano, Bari, Italy
}

(Received 29 April 2010; accepted 23 July 2010)

\begin{abstract}
A porcine group A rotavirus (GARV) strain, 61/07/Ire, was isolated from a 4-5 week asymptomatic piglet, during an epidemiological survey of porcine herds in Southern Ireland, in 2007. The nucleotide (nt) and amino acid (aa) sequence of the full-length VP4 protein of the PoRV strain 61/07/Ire was determined. Based on the entire VP4 open reading frame (nt), strain 61/07/Ire displayed $\leq 76.5 \%$ identity to representatives of the established 31 P-types, a value far lower than the percentage identity cutoff value (80\%) established by the Rotavirus Classification Working Group (RCWG) to define a novel P genotype. Strain $61 / 07 /$ Ire revealed low aa identity, ranging from $57.1 \%$ to $83.6 \%$, to the cognate sequences of representatives of the various $\mathrm{P}$ genotypes. The aa identity was lower in the VP8* trypsin-cleavage fragment of the VP4, which encompasses the VP4 hypervariable region, ranging from $36.9 \%$ to $75.3 \%$. Sequence analyses of the VP7, VP6, and NSP4 genes revealed that the GARV strain 61/07/Ire possessed a G2-like VP7, an E9 NSP4 genotype and an I5 VP6 genotype. Altogether, these results indicate that the GARV strain 61/07/Ire should be considered as a prototype of a new VP4 genotype, P[32], and provide further evidence for the vast heterogeneity of group A rotaviruses.
\end{abstract}

\section{Rotavirus / pig / VP4 / P genotype}

\section{INTRODUCTION}

Rotaviruses are classified into seven antigenically distinct groups (A to G). Groups A, B, and $\mathrm{C}$ are associated with acute gastroenteritis in humans and animals, while groups $\mathrm{D}, \mathrm{E}, \mathrm{F}$ and $\mathrm{G}$ have been detected only in animals $[10,25]$. In humans, group A rotavirus (GARV) is estimated to cause 138 million cases of gastroenteritis annually, resulting in approximately 619000 deaths, mostly in developing countries [21].

The rotavirus genome consists of 11 double stranded RNA segments, enclosed in a triple layered capsid. The outer capsid proteins, VP7

\footnotetext{
*Corresponding author: helen.oshea@cit.ie
}

and VP4 (defining the G-types and P-types, respectively), both elicit serotype-specific neutralising antibodies and are important for immune protection and for vaccine development $[10,23,65]$. To date, 23 G-types and 31 P-types have been identified in humans and animals [1, 26, 34, 36, 41, 44, 58-61, 63]. Rotavirus strains within a $\mathrm{G}$ serotype share at least 90-91\% VP7 amino acid (aa) sequence identity [10]. Rotavirus strains sharing $>89 \%$ VP4 aa sequence identities belong to the same $\mathrm{P}$ genotype, while those with $<89 \% \mathrm{VP} 4$ aa sequence identities belong to different $\mathrm{P}$ genotypes [17]. Moreover, the greatest aa divergence in VP4 is seen between aa 71 and 204 of the VP4 trypsin-cleavage product VP8*, which tends to correlate with VP4 serotype specificity [29, 30].

This is an Open Access article distributed under the terms of the Creative Commons Attribution-Noncommercial License (http://creativecommons.org/licenses/by-nc/3.0/), which permits unrestricted use, distribution, and reproduction in any noncommercial medium, provided the original work is properly cited. 
The middle capsid protein, VP6, bears the subgroup (SG) specificities which allow the classification of GARV into SG I, SG II, both SG I and II, or into neither SG, based on reactivity with SG specific monoclonal antibodies (MAbs) [10], or into genogroups I or II, based on sequence analysis of a fragment of the VP6 gene, known to correlate with SG specificity [24]. The non-structural glycoprotein NSP4 possesses enterotoxic activity, and has multiple functions in rotavirus morphogenesis and pathogenesis [10]. Sequence analyses of the NSP4 gene from human and animal rotavirus strains has revealed the presence of five distinct NSP4 genogroups, KUN- (A), Wa- (B), AU1- (C), EW- (D), and avian-like (E) [9, 47]. Rotavirus strains isolated from rabbits, horses, cows, and pigs generally cluster according to species of origin, and all PoRV strains identified to date cluster into NSP4 genogroup B, Wa-like $[9,40]$.

More recently, based on sequence comparison of large data sets, including full-length rotaviral genome sequences, a novel classification system was proposed, based on nucleotide identity cut-off percentages, and different genotypes were defined for each genome segment. An alpha-numeric letter code, Gx-P[x]-Ix-Rx-Cx$\mathrm{Mx}-\mathrm{Ax}-\mathrm{Nx}-\mathrm{Tx}-\mathrm{Ex}-\mathrm{Hx}$, is used to designate and classify the VP7-VP4-VP6-VP1-VP2VP3-NSP1-NSP2-NSP3-NSP4-NSP5/6 encoding genes, respectively [45]. Within this classification system, at least 13 VP6 genotypes (I1 to I13) and 12 NSP4 genotypes (E1 to E12), have been defined [45].

GARV are one of the most frequently detected viral agents associated with diarrhoea affecting piglets between 1 and 8 weeks of age [53]. GARV may also be detected in nondiarrheic piglets [31]. Infection of pigs with GARV has been recognised in both enzootic and epizootic forms of diarrhoea, resulting in economic losses in commercial piggeries [54]. Antigenic and molecular characterization of GARV has revealed a broad heterogeneity in the VP7 and VP4 genes. The most common G-types identified in pigs are G3, G4, G5 and G11, associated with common P-types, P[6] and $\mathrm{P}$ [7] [19]. Porcine GARV strains with additional P-types, P[13], P[19], P[23], P[26] and $\mathrm{P}[27]$ have also been described, but more sporadically. Furthermore, porcine strains displaying human-like G-types (G1, G2, G9 and G12) and P-types (M37-like P[6] and P[8]) and bovine-like G-types (G6, G8 and G10) and P-types (P[1], $\mathrm{P}[5]$ and $\mathrm{P}[11])$ have also been described $[6-8,16,19,20,35,38,40$, 41, 50].

Several epidemiological investigations have revealed that infections by unusual, animal-like strains, or animal-human rotavirus reassortants may not be infrequent in humans [57]. Therefore, the study of animal rotaviruses is pivotal to fully understand the evolution and ecology of human rotaviruses [39]. Also, this is fundamental for the development of new instruments to improve the prophylaxis of rotaviral diarrhea in piglets. Between 2005-2007, a surveillance study for rotavirus was conducted on Irish porcine herds in Southern Ireland. Porcine faecal samples were collected from asymptomatic animals and screened by molecular assays to detect GARV RNA. In this report, we describe a novel VP4 genotype carried by a G2-like PoRV strain, 61/07/Ire.

\section{MATERIALS AND METHODS}

\subsection{Sample collection}

Porcine GARV strain 61/07/Ire was identified during an epidemiological survey in Irish pig herds, in 2007. A total of 292 faecal samples were obtained from 4-5 week old asymptomatic pigs from porcine herds in Ireland, over 3 years, from 2005-2007. The samples were collected from 3 different herds in County Cork. Eighty samples were collected in May 2005 (farm 1), 80 samples were collected in September 2006 (farm 2) and 102 samples in May 2007 (farm 3). A collection of 30 samples (farm 4) was also obtained in March 2007, in County Dublin, from 8-9 week old piglets.

\subsection{RNA Preparation}

Total nucleic acids were extracted from the samples by a standard phenol-chloroform method with 
ethanol precipitation. The extracted nucleic acids were re-suspended in $100 \mu \mathrm{L}$ of sterile DEPC $\mathrm{H}_{2} \mathrm{O}$ and stored at $-80{ }^{\circ} \mathrm{C}$ prior to use.

\subsection{RT-PCR amplification of GARV and group $C$ rotavirus (GCRV)}

The extracted nucleic acids were tested for the presence GARV and GCRV by RT-PCR using oligonucleotide primers previously described $[15,55]$. For amplification of the VP7, the primer pair Beg9/End 9 was used [18]. Prediction of the VP7 (G) type was carried out by multiplex PCR as described in previous studies [13, 18, 20, 66]. Partial amplification of the VP6 gene was determined with primer pair VP6F-VP6R [24]. For amplification of the NSP4 gene, the primers 151 and 152 were used [5].

\subsection{RT-PCR amplification of the VP8* and VP4}

For amplification of the VP8* subunit of the VP4 gene, the primers Con 2 and Con3 were used [15]. Full-length amplification of the VP4 gene was achieved using the consensus primer 170 (ggt cac awc ctc tag mmr ytr ctt a) at the $3^{\prime}$ end of the genome segment in combination with primer Con3 [40].

\subsection{Sequence analysis}

The RT-PCR-amplified products were sequenced by Genome Express (Meylan, France). The sequences were assembled, edited and analyzed using the Bioedit software package version 2.1 [22]. Phylogenetic and molecular evolutionary analyses were conducted using MEGA version 2.1 (Arizona State University, USA) [28]. In addition, the sequences were analyzed using the web-based sequence analysis tool BLAST ${ }^{1}$. The full-length sequence of the VP4 strain 61/07/Ire has been assigned the accession number FJ492835 in the Genbank database. The partial VP8* sequence of strains, $2 \mathrm{~F} / 05 / \mathrm{Ire}, 60 / 07 / \mathrm{Ire}$, 1/07/Ire, 48/06/Ire, 2B/05/Ire and 2/07/Ire have been registered in the Genbank database as HM149304309 respectively. The partial sequences of the VP7 strains 48/07/Ire and 61/07/Ire have been registered under the accession numbers FJ492832 and FJ492831, respectively. The partial sequences of the NSP4 strains 48/07/Ire and 61/07/Ire have been assigned the accession numbers FJ492833 and FJ492834, respectively. The partial sequence of

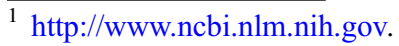

VP6 strains 61/07/Ire and 48/07/Ire have been registered as HM149310 and HM149311, respectively.

\section{RESULTS}

\subsection{RT-PCR screening for group $A$ and $C$ rotaviruses}

A total of 19 out of 292 samples $(6.5 \%)$ were found to contain GARV, while 13 samples (4.4\%) contained GCRV [11]. None of the GARV-positive samples were found to contain GCRV. The GARV positive samples were detected in 3/4 herds surveyed (2005-2007). GARV were detected in $6 / 80$ samples of the 2005 collection, 4/80 samples from 2006, 9/ 102 samples from 2007, all of which had been collected in County Cork. In addition, GARV infection was not diagnosed in 30 samples from the 2007 collection, made in County Dublin.

\subsection{Sequence analysis of the VP8* fragment of the VP4 gene}

The VP4 sequence of 15 out of 19 GARV samples was obtained while the sequence of four samples was not exploitable for further analyses. Sequence analysis allowed characterization of the majority of the strains as $\mathrm{P}[6]$, $\mathrm{P}[7], \mathrm{P}[13], \mathrm{P}[13] / \mathrm{P}[22]$ and $\mathrm{P}[26]$. However, two strains, 48/07/Ire and 61/07/Ire, were distantly related to representative rotavirus strains of established P genotypes (Fig. 1). Based on the VP8* fragment (about 880 bp), strain 48/ $07 /$ Ire and $61 / 07 /$ Ire displayed $>98 \%$ nucleotide identity to each other, therefore, the sequence of the full-length VP4 gene of one such strain, 61/ 07/Ire, was determined. The basic structure of the VP4 gene of the Irish strain was very similar to those of other rotavirus strains, in that it consisted of $2362 \mathrm{bp}$ with one open reading frame (ORF) beginning at nucleotide 10, and a single TAA stop codon at nucleotide 2 238. The predicted size of the porcine VP4 protein was 776 aa, similar to those of most rotavirus strains, which are 775 or 776 aa in length [10]. The deduced aa sequence of the VP4 of the PoRV strains 61/07/Ire was compared with those of representative rotavirus strains of the 


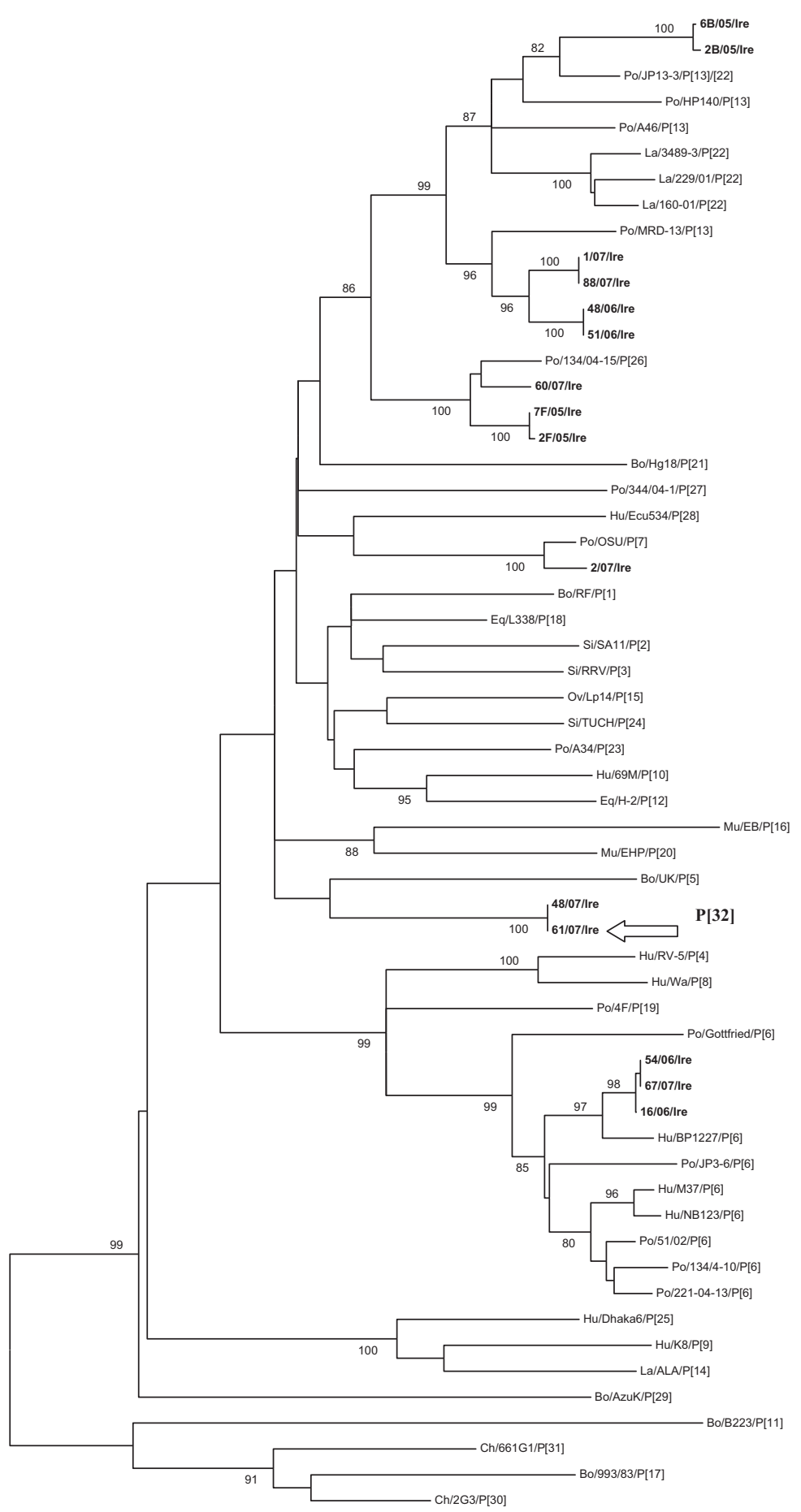

Figure 1. Neighbor-joining phylogenetic tree (2362 bp) of the VP4 nucleotide sequences displaying the Page 4 of 12 (page number not for citation purpose) 
majority of the $\mathrm{P}$ genotypes. The conserved prolines and cysteines, and the potential trypsin-cleavage sites [2] were maintained in the VP4 of the Irish strain (data not shown). The additional cleavage sites identified in the VP5*, Lys-259, and putatively, Arg-467 [12], were also conserved (data not shown). The aa sequence of the full-length VP4 protein of PoRV strain 61/07/Ire showed aa identity values, ranging from $57.1 \%$ to $83.6 \%$ when compared to those of strains representatives of all $\mathrm{P}$ genotypes (Tab. I). Likewise, the aa sequence of the VP8* of 61/07/Ire shared low aa identity (36.9-75.3\%), with the homologous sequences of representative strains of other $\mathrm{P}$ genotypes (Tab. I). Sequence comparison based on the nucleotide alignment of representative of the various $\mathrm{P}$ genotypes (Tab. I), and analysis by BLAST also revealed that in the 4th dsRNA segment strain 61/07/Ire shared $<76.5 \% \mathrm{nt}$ identity with all the GARV strains identified thus far. This value is below the cutoff value proposed by Matthijnssens et al. [44] for the VP4 gene (80\%).

\subsection{Sequence analysis of the gene encoding the outer capsid protein VP7}

By PCR genotyping using several pools of G-type specific primers [13, 18, 20, 66], strains 48/07/Ire and 61/07/Ire remained uncharacterized. Sequence analysis of the VP7 gene allowed the characterization of such untypeable GARV, 48/07/Ire and 61/07/Ire, as G2-like strains. A phylogenetic tree was constructed with a selection of human and porcine G2 strains. Two major lineages were observed, with one including the human G2 strains, and the other lineage consisting exclusively of porcine G2-like strains (Fig. 2).

The VP7 gene segments of strains 48/07/Ire and 61/07/Ire displayed the highest aa identity
(92.4-93\%) to the porcine strain 34461/4, the reference G2-like porcine strain, identified in Spain [38]. The Irish G2-like strains displayed 12 and $7 \mathrm{nt}$ mismatches in the binding sites of the G2-specific primers aCT2 and 9T1-2, respectively $[13,18]$, that likely prevented recognition by the genotyping probes (data not shown). In the VP7 antigenic regions A (aa 87 to 101 ), B (aa 141 to 152 ), C (aa 208 to $224)$ and $F$ (235 to 242) [7, 14, 27, 48], strain 48/07/Ire differed in 9 residues and 61/07/Ire differed in 8 residues from the prototype G2like porcine strain $34461 / 4$ (data not shown).

\subsection{NSP4 and VP6 analysis}

In the NSP4-based tree (Fig. 3), strains 48/ $07 /$ Ire and $61 / 07 /$ Ire were clustered with the human strain A_G4_120 and the porcine strains P21-5 and $\mathrm{CMP} 03 \overline{4}$, within the E9 genotype, while the vast majority of porcine viruses are E1. In the NSP4, strain 48/07/Ire and 61/07/ Ire displayed $99 \%$ nucleotide identity to each other. The Irish GARV strains displayed the highest nt identity (93.6-93.9\%) to E9 strains (P21-5, CMP034 and A_G4_120), while nt identity to other E types was lower than the established cutoff value (85\%).

The VP6 genotype was determined by amplification of a 379-bp fragment, spanning from amino acids 241 to 367 of the VP6, with primer pair VP6F-VP6R [24]. In the VP6, strain $48 / 07 /$ Ire and $61 / 07 /$ Ire displayed only $83.1 \%$ nucleotide identity to each other. Based on this short fragment, strain 48/07/Ire closely resembled human SGII ( $\leq 99.2 \%$ nt identity), within the I1 genotype, while strain 61/07/Ire resembled porcine SGI strains $(92.6 \%$ nt identity to porcine strain $\mathrm{CM}$ ), within the I5 genotype (Fig. 4). Accordingly, the two Irish strains possessed a diverse VP6 gene, likely due to a reassortment event.

relationship between strains 61/07/Ire (designated with an arrow and referred to as $\mathrm{P}[32])$ with all the known P genotypes. Genbank accession of the VP4 sequences are in Table I. Abbreviations: Si, simian; Eq, equine; Po, porcine; Ca, canine; Bo, bovine; Mu, murine; Hu, human; Ov, ovine; La, lapine. All phylogenetic trees in this study were statistically supported by bootstrapping of 500 replicates. Bootstrap values below $80 \%$ were not shown in the phylogenetic trees in this study. The scale bar represents 0.1 substitutions per site. 
Table I. Comparison of the nucleotide and amino acid sequences of VP8*, VP5* and VP4 of porcine strain $61 / 07 /$ Ire with those of representatives of established P genotypes. Abbreviations: Si, simian; Eq, equine; Po, porcine; Bo, bovine; $\mathrm{Hu}$, human; Ov, ovine; $\mathrm{Ca}$, caprine; $\mathrm{Mu}$, murine. In boldface the highest identity matches.

\begin{tabular}{|c|c|c|c|c|}
\hline Species/Strain/Accession No/P type & VP4 (nt) & VP8* (aa) & VP5 (aa) & VP4 (aa) \\
\hline $\mathrm{Bo} / \mathrm{RF} / \mathrm{U} 65924 / \mathrm{P}[1]$ & 73.1 & 69.8 & 83.9 & 78.9 \\
\hline $\mathrm{Si} / \mathrm{SA} 11 / \mathrm{M} 23188 / \mathrm{P}[2]$ & 73.7 & 71.5 & 84.7 & 80 \\
\hline $\mathrm{Si} / \mathrm{RRV} / \mathrm{M} 18736 / \mathrm{P}[3]$ & 72.3 & 71.5 & 83.7 & 79.3 \\
\hline $\mathrm{Ca} / \mathrm{K} 9 / \mathrm{D} 14725 / \mathrm{P}[3]$ & 73.1 & 69.4 & 85.4 & 79.6 \\
\hline $\mathrm{Hu} / \mathrm{RV}-5 / \mathrm{M} 32559 / \mathrm{P}[4]$ & 69.9 & 59.4 & 75.9 & 70.6 \\
\hline $\mathrm{Bo} / \mathrm{UK} / \mathrm{M} 22306 / \mathrm{P}[5]$ & 68.8 & 61.9 & 77.6 & 72.1 \\
\hline Hu/M37/L20877/P[6] & 69.3 & 61 & 79 & 73.1 \\
\hline Po/Gottfried/M33516/P[6] & 68.5 & 60.6 & 77.2 & 72 \\
\hline Po/OSU/X13190/P[7] & 75.1 & 71.9 & 86.6 & 81.5 \\
\hline $\mathrm{Hu} / \mathrm{Wa} / \mathrm{M} 96825 / \mathrm{P}[8]$ & 69.8 & 59.4 & 75.3 & 70.2 \\
\hline $\mathrm{Hu} / \mathrm{K} 8 / \mathrm{D} 90260 / \mathrm{P}[9]$ & 65.5 & 55.6 & 73.6 & 67.7 \\
\hline $\mathrm{Hu} / 69 \mathrm{M} / \mathrm{M} 60600 / \mathrm{P}[10]$ & 72.5 & 69.4 & 84.3 & 79.2 \\
\hline Bo/B223/D13394/P[11] & 59.3 & 36.9 & 67.1 & 57.1 \\
\hline $\mathrm{Eq} / \mathrm{H}-2 / \mathrm{L} 04638 / \mathrm{P}[12]$ & 71 & 64.8 & 83 & 76.9 \\
\hline $\mathrm{Po} / \mathrm{A} 46 / \mathrm{AY} 050274 / \mathrm{P}[13]$ & 75.9 & 66.3 & 87.7 & 80.4 \\
\hline $\mathrm{Hu} / \mathrm{Pa} 169 / \mathrm{D} 14724 / \mathrm{P}[14]$ & 66.3 & 58.1 & 74.4 & 69 \\
\hline Ov/Lp14/L11599/P[15] & 72.3 & 69.8 & 83.3 & 78.8 \\
\hline $\mathrm{Mu} / \mathrm{EB} / \mathrm{L} 18992 / \mathrm{P}[16]$ & 66.5 & 55.2 & 78.6 & 71 \\
\hline Bo/993/83/D16352/P[17] & 62.5 & 41.4 & 70.2 & 60.8 \\
\hline Eq/L338/D13399/P[18] & 72.9 & 67.7 & 82.4 & 77.7 \\
\hline $\mathrm{Po} / 4 \mathrm{~F} / \mathrm{L} 10359 / \mathrm{P}[19]$ & 69.8 & 59.8 & 79.9 & 73.3 \\
\hline Mu/EHP/U08424/P[20] & 69.1 & 67.7 & 81.2 & 76.6 \\
\hline $\mathrm{Bo} / \mathrm{Hg} 18 / \mathrm{AF} 237665 / \mathrm{P}[21]$ & 72 & 62.3 & 83.3 & 76.4 \\
\hline $\mathrm{La} / 160 / 01 / \mathrm{AF} 526374 / \mathrm{P}[22]$ & nd & 65.1 & nd & nd \\
\hline $\mathrm{Po} / \mathrm{A} 34 / \mathrm{AY} 174094 / \mathrm{P}[23]$ & nd & 64 & nd & nd \\
\hline Si/TUCH/AY596189/P[24] & 71.5 & 70.2 & 84.7 & 79.7 \\
\hline Hu/Dhaka6/AY773004/P[25] & 66.4 & 56 & 72.7 & 67.1 \\
\hline $\mathrm{Po} / 134 / 04-15 / \mathrm{DQ} 061053 / \mathrm{P}[26]$ & 76.5 & 75.3 & 87.7 & 83.6 \\
\hline $\mathrm{Po} / 344 / 04-1 / \mathrm{DQ} 242615 / \mathrm{P}[27]$ & 69.9 & 61 & 78.6 & 72.8 \\
\hline $\mathrm{Hu} /$ Ecu534/EU805773/P[28] & 69.8 & 64 & 81.1 & 75.3 \\
\hline $\mathrm{Bo} / \mathrm{AzuK} / \mathrm{AB} 454420 / \mathrm{P}[29]$ & 64.5 & 47.3 & 70 & 62.3 \\
\hline $\mathrm{Ch} / \mathrm{Ch}-2 \mathrm{G} 3 / \mathrm{EU} 486956 / \mathrm{P}[30]$ & 60.9 & 42.6 & 68.9 & 59.9 \\
\hline $\mathrm{Ch} / \mathrm{Ch}-661 \mathrm{G} 1 / \mathrm{EU} 486962 / \mathrm{P}[31]$ & 61.9 & 41 & 69.7 & 60.2 \\
\hline
\end{tabular}

\section{DISCUSSION}

A surveillance study was conducted in Southern Ireland, to investigate the diversity of GARV strains circulating in asymptomatic animals in porcine herds in Ireland from 2005-2007. Sequence analysis of the VP7 and the VP4 genes of the strains detected in this study identified a spectrum of $\mathrm{G}$ and $\mathrm{P}$ genotypes, including
G2-like, G4, G5, G9, G11, P[7], P[13], and $\mathrm{P}[26]$. In addition, sequence analysis of the VP8* subunit of the VP4 gene (Fig. 1) identified two GARV strains, 48/07/Ire and 61/07/Ire, which could not be placed into any of the previously established VP4 genotypes. Epidemiological studies from diverse geographical settings worldwide have demonstrated the existence of several novel $\mathrm{P}$ genotypes in pigs $[26,40,41,60]$. 


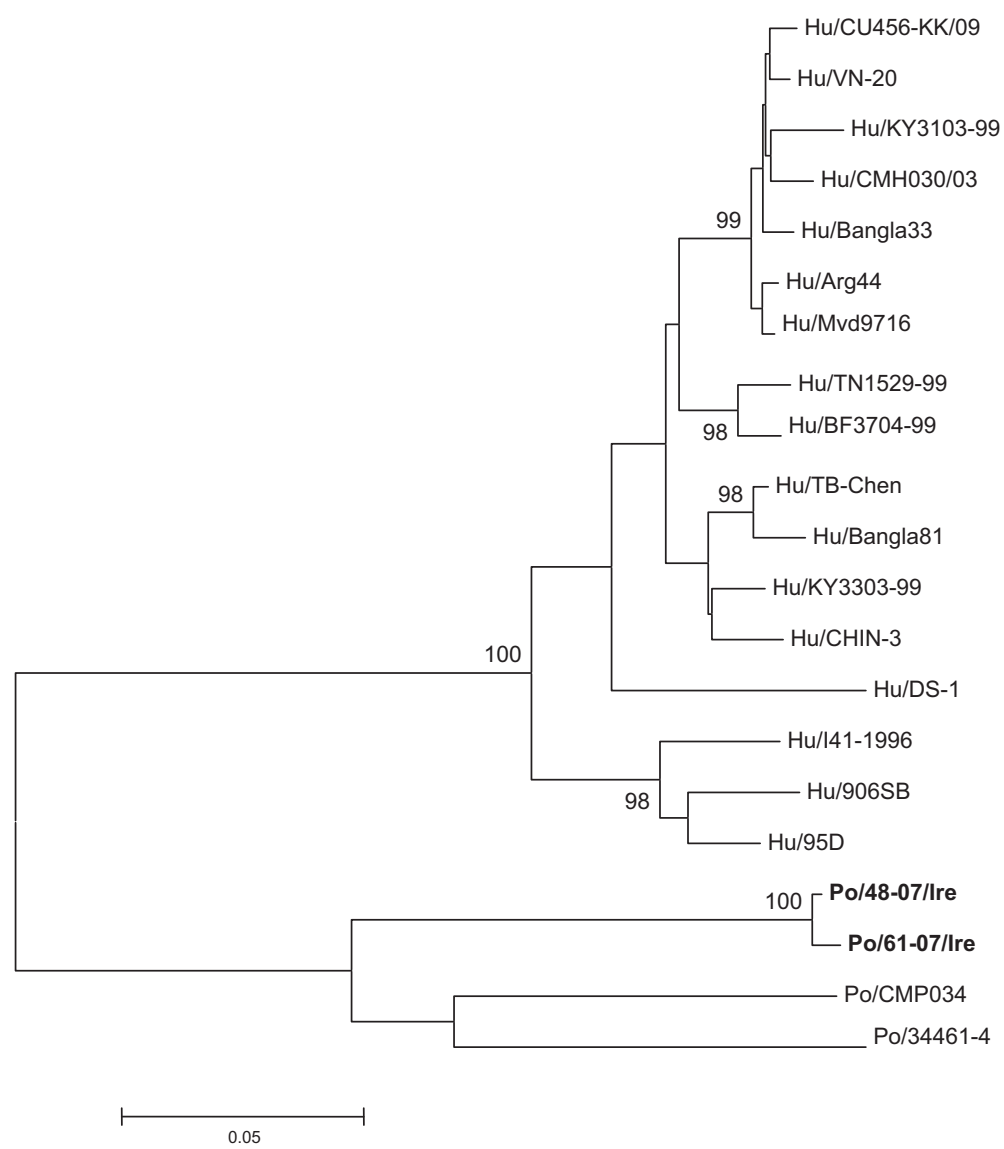

Figure 2. Neighbor-joining phylogenetic tree $(920 \mathrm{bp})$ based on the VP7 nucleotide sequences of various porcine G2-like and human G2 porcine strains with porcine strains 48/07/Ire and 61/07/Ire. The Irish porcine strains are highlighted in bold. The scale bar represents 0.05 substitutions per site.

The GARV strains 48/07/Ire and 61/07/Ire were collected from 4-5 week old piglets in the same farm in County Cork, in 2007. Based on analysis of the VP4, strain 61/07/Ire displayed the highest identity $(83.6 \%$ aa) to strain Po/134/04-15 [40]. By comparing the nt sequence of the entire VP4 ORF, the strain $61 / 07 /$ Ire displayed $\leq 76.5 \%$ identity to all other VP4 full-length sequences available in the databases, a value which was far lower than the percentage identity cutoff value $(80 \%)$ established by the Rotavirus Classification Working Group (RCWG) to define a novel P genotype [44]. The sequence was submitted to the RCWG and was assigned a new P genotype, $\mathrm{P}[32]$.

Analysis of the VP7 gene identified strains 48/07/Ire and 61/07/Ire as G2-like, since they displayed the highest aa identity (92.4-93\%) to the G2-like porcine strain 34461-4. G2-like strains have been identified in pigs in Europe [38] and in Asia [26]. These porcine VP7 genes are similar to human $\mathrm{G} 2$ viruses, although they cluster clearly in a separate mono-phyletic branch.

When the NSP4 gene sequence was analysed, the Irish strains 48/07/Ire and 61/07/Ire were placed separately from rotaviruses of the 


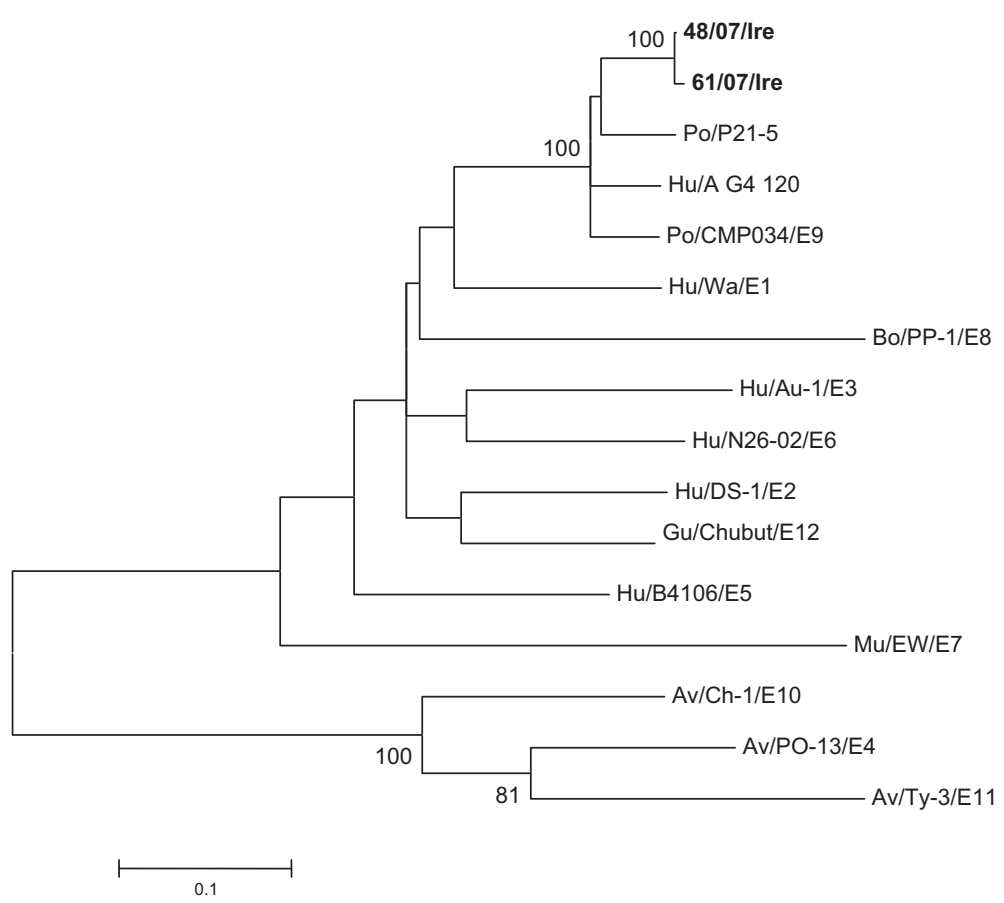

Figure 3. Neighbor-joining phylogenetic tree $(729 \mathrm{bp})$ based on the NSP4 reference strains, E1-E12. The scale bar represents 0.1 substitutions per site.

E1 genotype, which encompasses the majority of porcine viruses. Interestingly, the Irish strains 48/07/Ire and 61/07/Ire clustered with a small group of viruses, including the unusual human strain A G4 120 and the porcine strains P215 and $\mathrm{C} \overline{\mathrm{MP}} 0 \overline{3} 4$, within the E9 genotype. Phylogenetic analyses of the VP6 gene revealed that strain 61/07/Ire resembled porcine strains of genotype I5. Conversely, strain 48/07/Ire clustered with genotype I1 viruses. Therefore, 61/ 07/Ire possessed a different VP6 gene, suggesting a genetic reassortment. Since different strains were found to co-circulate at the same time in each of the examined herd (three strains in farm 1, two in farm 2 and seven in farm 3 ). Reassortment is frequent among rotaviruses and, along with positive accumulation of single point mutations, inter-segmental recombination, rearrangement, and inter-species transmission, contributes to their evolution $[10,42]$.

In recent years, rotavirus surveillance has intensified throughout the world, monitoring the appearance of novel antigenic types and providing evidence for a significant genetic/ antigenic diversity of GARV. Together with data presented in this study, at least 32 rotavirus $\mathrm{P}$ genotypes and several novel lineages within the epidemiologically relevant human VP4 genotypes (e.g. P[8] and $\mathrm{P}[6]$ ) have been recognized, some of which presumably account for novel antigenic $P$ types or subtypes [3, 4, 32, 33, 37, 46, 49, 51, 52].

Along with cattle, pigs are regarded as important reservoirs for human rotavirus diversification, and there is evidence that heterologous rotaviruses of porcine origin or porcine-human reassortants may have occurred and spread successfully throughout human populations in a few occasions in Latin America $[43,56]$, South East Asia [62, 64] and Europe $[4,39]$. Human GARV with unusual G-types such as G5, G6, G8, G9, G10, G11 and G12 associated with P-types $\mathrm{P}[3], \mathrm{P}[6], \mathrm{P}[9]$, $\mathrm{P}[11], \mathrm{P}[14]$ and $\mathrm{P}[25]$ have been detected 


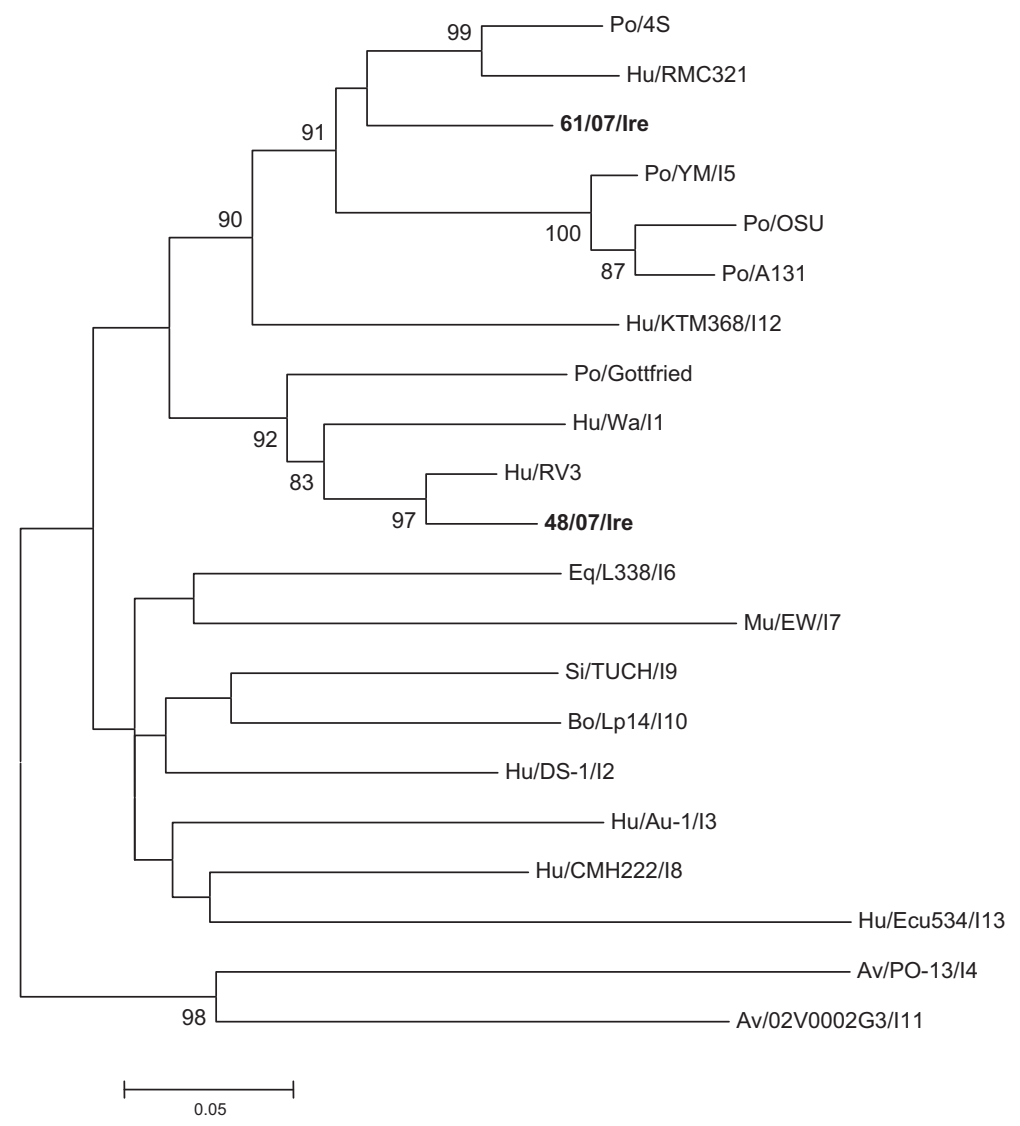

Figure 4. Neighbor-joining phylogenetic tree $(379 \mathrm{bp})$ based on the VP6 reference strains, I1-I13. The scale bar represents 0.05 substitutions per site.

$[51,57]$. Therefore, mapping the precise distribution of rotavirus $\mathrm{G}$ and P-types in the various animal species is important to provide a baseline to readily identify the source of atypical GARV infections in humans. Also, it is important to develop more effective tools for the prophylaxis of rotaviral diarrhea in animals. A better understanding of rotavirus epidemiology will help understanding the global ecology and the evolution of rotaviruses.

Acknowledgements. The authors wish to thank Bill Cashman for stimulating discussions and for assistance with the collection of specimens. This work was funded by Technological Research Sector Strand 1 (PO 6176) and FIRM research grants $(05 / \mathrm{R} \& \mathrm{D} / \mathrm{CIT} /$ 365) awarded to Helen O'Shea.

\section{REFERENCES}

[1] Abe M., Ito N., Morikawa S., Takasu M., Murase T., Kawashima T., et al., Molecular epidemiology of rotaviruses among healthy calves in Japan: isolation of a novel bovine rotavirus bearing new $P$ and $G$ genotypes, Virus Res. (2009) 144:250-257.

[2] Arias C.F., Romero P., Alvarez V., Lopez S., Trypsin activation pathway of rotavirus infectivity, J. Virol. (1996) 70:5832-5839.

[3] Arista S., Giammanco G.M., De Grazia S., Colomba C., Martella V., Genetic variability among serotype G4 Italian human rotaviruses, J. Clin. Microbiol. (2005) 43:1420-1425.

[4] Bányai K., Martella V., Jakab F., Melegh B., Szücs G., Sequencing and phylogenetic analysis of human genotype $\mathrm{P}[6]$ rotavirus strains detected in 
Hungary provides evidence for genetic heterogeneity within the P[6] VP4 gene, J. Clin. Microbiol. (2004) 42:4338-4443.

[5] Banyai K., Bogdan A., Szucs G., Arista S., De Grazia S., Kang G., et al., Assignment of the group A rotavirus NSP4 gene into genogroups using a heminested PCR assay: a rapid and reproducible assay for strain surveillance, J. Med. Microbiol. (2009) 58:303311.

[6] Chan-It W., Khamrin P., Saekhow P., Pantip C., Thongprachum A., Peerakome S., et al., Multiple combinations of P[13]-like genotype with G3, G4, and G5 in porcine rotaviruses, J. Clin. Microbiol. (2008) 46:1169-1173.

[7] Ciarlet M., Ludert J.E., Liprandi F., Comparative amino acid sequence analysis of the major outer capsid protein (VP7) of porcine rotaviruses with G3 and G5 serotype specificities isolated in Venezuela and Argentina, Arch. Virol. (1995) 140:437-451.

[8] Ciarlet M., Hoshino Y., Liprandi F., Single point mutations may affect the serotype reactivity of serotype G11 porcine rotavirus strains: a widening spectrum?, J. Virol. (1997) 71:8213-8220.

[9] Ciarlet M., Liprandi F., Conner M.E., Estes M.K., Species specificity and interspecies relatedness of NSP4 genetic groups by comparative NSP4 sequence analyses of animal rotaviruses, Arch. Virol. (2000) 145:371-383.

[10] Ciarlet M., Estes M.K., Rotaviruses: basic biology, epidemiology and methodologies, in: Bitton G. (Ed.), Encyclopedia of Environmental Microbiology, John Wiley and Sons, New York, USA, 2002, pp. 2753-2773.

[11] Collins P.J., Martella V., O'Shea H., Detection and characterization of Group $\mathrm{C}$ Rotaviruses in asymptomatic piglets in Ireland, J. Clin. Microbiol. (2008) 46:2973-2979.

[12] Crawford S.E., Mukherjee S.K., Estes M.K., Lawton J.A., Shaw A.L., Ramig R.F., Prasad B.V., Trypsin cleavage stabilizes the rotavirus VP4 spike, J. Virol. (2001) 75:6052-6061.

[13] Das B.K., Gentsch J.R., Cicirello H.G., Woods P.A., Gupta A., Ramachandran M., et al., Characterization of rotavirus strains from newborns in New Delhi, India, J. Clin. Microbiol. (1994) 32:1820-1822.

[14] Dyall-Smith M.L., Lazdins I., Tregear G.W., Holmes I.H., Location of the major antigenic sites involved in rotavirus serotype-specific neutralization, Proc. Natl. Acad. Sci. USA (1986) 83:3465-3468.

[15] Gentsch J.R., Glass R.I., Woods P., Gouvea V., Gorziglia M., Flores J., et al., Identification of group A rotavirus gene 4 types by polymerase chain reaction, J. Clin. Microbiol. (1992) 30:1365-1373.

[16] Ghosh S., Varghese V., Samajdar S., Bhattacharya S.K., Kobayashi N., Naik T.N., Molecular characterization of a porcine group A rotavirus strain with G12 genotype specificity, Arch. Virol. (2006) 151:1329-1344.

[17] Gorziglia M., Larralde G., Kapikian A., Chanock R.M., Antigenic relationships among human rotaviruses as determined by outer capsid protein VP4, Proc. Natl. Acad. Sci. USA (1990) 87:7155-7159.

[18] Gouvea V., Glass R.I., Woods P., Taniguchi K., Clark H.F., Forrester B., Fang Z.Y., Polymerase chain reaction amplification and typing of rotavirus nucleic acid from stool specimens, J. Clin. Microbiol. (1990) 28:276-282.

[19] Gouvea V., Santos N., Timenetsky M.C., Identification of bovine, porcine rotavirus G types by PCR, J. Clin. Microbiol. (1994) 32:1338-1340.

[20] Gouvea V., Santos N., Timenetsky M.C., VP4 typing of bovine and porcine group A rotaviruses by PCR, J. Clin. Microbiol. (1994) 32:1333-1337.

[21] World-Health-Organization, External review of burden of disease attributable to rotavirus, 30 November to 1 December 2005, World Health Organization, Geneva, Switzerland.

[22] Hall T.A., BioEdit: a user-friendly biological sequence alignment and analysis program for Windows 95/98/NT, Nucl. Acids Symp. Ser. (1999) 41:95-98.

[23] Heaton P.M., Ciarlet M., The pentavalent rotavirus vaccine: Discovery to licensure and beyond, Infect. Clin. Dis. (2007) 45:1618-1624.

[24] Iturriza Gómara M., Wong C., Blome S., Desselberger U., Gray J., Rotavirus subgroup characterisation by restriction endonuclease digestion of a cDNA fragment of the VP6 gene, J. Virol. Methods (2002) 105:99-103.

[25] Kapikian A.Z., Hoshino Y., Chanock R.M., Rotaviruses, in: Knipe D.M., Howley P.M., Griffin D.E., Lamb R.A., Martin M.A., Roizman B., Strais S.E. (Eds.), Fields Virology, 4th edition, Lippincott Williams and Wilkins, Philadelphia, 2001, pp. 1787 1833.

[26] Khamrin P., Maneekarn N., Peerakome S., Chan-it W., Yagyu F., Okitsu S., Ushijima H., Novel porcine rotavirus of genotype $\mathrm{P}[27]$ shares new phylogenetic lineage with G2 porcine rotavirus strain, Virology (2007) 361:243-252.

[27] Kobayashi N., Taniguchi K., Urasawa S., Analysis of the newly identified neutralization epitopes on 
VP7 of human rotavirus serotype 1, J. Gen. Virol. (1991) 72:117-124.

[28] Kumar S., Tamura K., Jakobsen I.B., Nei M., MEGA2: Molecular evolutionary genetics analysis software, Bioinformatics (2001) 17:1244-1245.

[29] Larralde G., Kapikian L.B., Gorziglia M., Serotype-specific epitope(s) present on the VP8* subunit of rotavirus VP4, J. Virol. (1991) 65:3213-3218.

[30] Larralde G., Gorziglia M., Distribution of conserved and serotype-specific epitopes on the VP8* subunit of rotavirus VP4, J. Virol. (1992) 72:117-124.

[31] Lecce J.G., King M.W., Role of rotavirus (reolike) in weanling diarrhea of pigs, J. Clin. Microbiol. (1978) 8:454-458.

[32] Lee J.B., Youn S.J., Nakagomi T., Park S.Y., Kim T.J., Song C.S., et al., Isolation, serologic and molecular characterization of the first G3 caprine rotavirus, Arch. Virol. (2003) 148:643-657.

[33] Lennon G., Reidy N., Cryan B., Fanning S., O'Shea H., Changing profile of Rotavirus in Ireland: Predominance of $\mathrm{P}[8]$ and emergence of $\mathrm{P}[6]$ and $\mathrm{P}[9]$ in mixed infections, J. Med. Virol. (2008) 80:524-530.

[34] Liprandi F., Gerder M., Bastidas Z., Lopez J.A., Pujol F.H., Ludert J.E., et al., A novel type of VP4 carried by a porcine rotavirus strain, Virology (2003) 315:373-380.

[35] Martella V., Pratelli A., Greco G., Tempesta M., Ferrari M., Losio M.N., Buonavoglia C., Genomic characterization of porcine rotaviruses in Italy, Clin. Diagn. Lab. Immunol. (2001) 8:129-132.

[36] Martella V., Ciarlet M., Camarda A., Pratelli A., Tempesta M., Greco G., et al., Molecular characterization of the VP4, VP6, VP7, and NSP4 genes of lapine rotaviruses identified in Italy: emergence of a novel VP4 genotype, Virology (2003) 314:358-370.

[37] Martella V., Ciarlet M., Pratelli A., Arista S., Terio V., Elia G., et al., Molecular analysis of the VP7, VP4, VP6, NSP4, and NSP5/6 genes of a buffalo rotavirus strain: identification of the rare $\mathrm{P}[3]$ rhesus rotavirus-like VP4 gene allele, J. Clin. Microbiol. (2003) 41:5665-5675.

[38] Martella V., Ciarlet M., Baselga R., Arista S., Elia G., Lorusso E., et al., Sequence analysis of the VP7 and VP4 genes identifies a novel VP7 gene allele of porcine rotaviruses, sharing a common evolutionary origin with human G2 rotaviruses, Virology (2005) 337:111-123.

[39] Martella V., Bányai K., Ciarlet M., IturrizaGomara M., Lorusso E., De Grazia S., et al., Relationships among porcine and human $\mathrm{P}[6]$ rotaviruses: evidence that the different human $\mathrm{P}[6]$ lineages have originated from multiple interspecies transmission events, Virology (2006) 344:509-519.

[40] Martella V., Ciarlet M., Bányai K., Lorusso E., Cavalli A., Corrente M., et al., Identification of a novel VP4 genotype carried by a serotype G5 porcine rotavirus strain, Virology (2006) 346:301-311.

[41] Martella V., Ciarlet M., Banyai K., Lorusso E., Arista S., Lavazza A., et al., Identification of group A porcine rotavirus strains bearing a novel VP4 (P) genotype in Italian Swine Herds, J. Clin. Microbiol. (2007) 45:577-580.

[42] Martella V., Bányai K., Matthijnssens J., Buonavoglia C., Ciarlet M., Zoonotic aspects of rotaviruses, Vet. Microbiol. (2010) 140:246-255.

[43] Mascarenhas J.D., Linhares A.C., Gabbay Y.B., Leite J.P., Detection and characterization of rotavirus $G$ and $P$ types from children participating in a rotavirus vaccine trial in Belem, Brazil. Mem. Inst. Oswaldo Cruz (2002) 97:113-117.

[44] Matthijnssens J., Ciarlet M., Heiman E., Arijs I., Delbeke T., McDonald S., et al., Full genome-based classification of rotaviruses reveals common origin between human Wa-like and Porcine rotavirus strains and human DS-1-like and bovine rotavirus strains, J. Virol. (2008) 82:3204-3219.

[45] Matthijnssens J., Ciarlet M., Rahman M., Attoui H., Bányai K., Estes M.K., et al., Recommendations for the classification of group A rotaviruses using all 11 genomic RNA segments, Arch. Virol. (2008) 153:1621-1629.

[46] McNeal M.M., Sestak K., Choi A.H., Basu M., Cole M.J., Aye P.P., et al., Development of a rotavirusshedding model in rhesus macaques, using a homologous wild-type rotavirus of a new P genotype, J. Virol. (2005) 79:944-954.

[47] Mori Y., Borgan M.A., Ito N., Sugiyama M., Minamoto N., Diarrhea-inducing activity of avian rotavirus NSP4 glycoproteins, which differ greatly from mammalian rotavirus NSP4 glycoproteins in deduced amino acid sequence in suckling mice, $\mathrm{J}$. Virol. (2002) 76:5829-5834.

[48] Nishikawa K., Hoshino Y., Taniguchi K., Green K.Y., Greenberg H.B., Kapikian A.Z., et al., Rotavirus VP7 neutralization epitopes of serotype 3 strains, Virology (1989) 171:503-515.

[49] Okada N., Matsumoto Y., Bovine rotavirus G and $\mathrm{P}$ types and sequence analysis of the VP7 gene of two G8 bovine rotavirus from Japan, Vet. Microbiol. (2002) 84:297-305.

[50] Parra G.I., Vidales G., Gomez J.A., Fernandez F.M., Parreno V., Bok K., Phylogenetic analysis of porcine rotavirus in Argentina: Increasing diversity of 
G4 strains and evidence of interspecies transmission, Vet. Microbiol. (2008) 126:243-250.

[51] Rahman M., Matthijnssens J., Nahar S., Podder G., Sack D.A., Azim T., Van Ranst M., Characterization of a novel P[25],G11 group A rotavirus, J. Clin. Microbiol. (2005) 43:3208-3212.

[52] Rao C.D., Gowda K., Reddy B.S.Y., Sequence analysis of VP4 and VP7 genes of nontypeable strains identifies a new pair of outer capsid proteins representing novel $\mathrm{P}$ and $\mathrm{G}$ genotypes in bovine rotaviruses, Virology (2000) 276:104-113.

[53] Saif L.J., Rosen B., Parwani A., Animal Rotaviruses, in: Kapikian A. (Ed.), Viral infections of the gastrointestinal tract, Marcel Dekker, Inc., New York, 1994, pp. 279-367.

[54] Saif L.J., Fernandez F.M., Group A rotavirus veterinary vaccines, J. Infect. Dis. (1996) 174:S98S106.

[55] Sanchez-Fauquier A., Roman E., Colomina J., Wilhelmi I., Glass R.I., Jiang B., First detection of group $\mathrm{C}$ rotavirus in children with acute diarrhoea in Spain, Arch. Virol. (2003) 148:399-404.

[56] Santos N., Volotão E.M., Soares C.C., Albuquerque M.C.M., da Silva F.M., Chizhikov V., Hoshino Y., VP7 gene polymorphism of serotype G9 rotavirus strand its impact on $\mathrm{G}$ genotype determination by PCR, Virus Res. (2002) 90:1-14.

[57] Santos N., Hoshino H., Global distribution of rotavirus serotypes/genotypes and its implication for the development and implementation of an effective vaccine, Rev. Med. Virol. (2005) 15:29-56.

[58] Schumann T., Hotzel H., Otto P., Johne R., Evidence of interspecies transmission and reassortment among avian group A rotaviruses, Virology (2009) 386:334-343.

[59] Solberg O.D., Hasing M.E., Trueba G., Eisenberg J.N., Characterization of novel VP7, VP4, and
VP6 genotypes of a previously untypeable group A rotavirus, Virology (2009) 385:58-67.

[60] Steyer A., Poljsak-Prijatelj M., Barlic-Maganja D., Jamnikar U., Mijovski J.Z., Marin J., Molecular characterization of a new porcine rotavirus $\mathrm{P}$ genotype found in an asymptomatic pig in Slovenia, Virology (2006) 359:275-282.

[61] Trojnar E., Otto P., Johne R., The first complete genome sequence of a chicken group A rotavirus indicates independent evolution of mammalian and avian strains, Virology (2009) 386:325-333.

[62] Urasawa S., Hasegawa A., Taniguchi T., Wakasugi F., Suzuki H., Inouve S., et al., Antigenic and genetic analyses of human rotaviruses in Chiang Mai, Thailand: evidence for a close relationship between human and animal rotaviruses, J. Infect. Dis. (1992) 166:227-234.

[63] Ursu K., Kisfali P., Rigó D., Ivanics E., Erdélyi K., Dán A., et al., Molecular analysis of the VP7 gene of pheasant rotaviruses identifies a new genotype designated G23, Arch. Virol. (2009) 154:1365-1369.

[64] Varghese V., Das S., Singh N.B., Kojima K., Bhattacharya S.K., Krishnan T., et al., Molecular characterization of a human rotavirus reveals porcine characteristics in most of the genes including VP6 and NSP4, Arch. Virol. (2004) 149:155-172.

[65] Vesikari T., Matson D., Dennehy P., Van Damme P., Santosham M., Rodriguez Z., et al., Safety and efficacy of a pentavalent human-bovine (WC3) reassortant rotavirus vaccine, N. Engl. J. Med. (2006) 354:23-33.

[66] Winiarczyk S., Paul P.S., Mummidi S., Panek R., Gradzki Z., Survey of porcine rotavirus $G$ and $P$ genotype in Poland and the United States using RT-PCR, J. Vet. Med. B Infect. Dis. Vet. Public Health (2002) 49:373-378. 